\title{
Efficient generation of patient-matched malignant and normal primary cell cultures from clear cell renal cell carcinoma patients: clinically relevant models for research and personalized medicine
}

Nazleen C. Lobo' ${ }^{1}$ Craig Gedye², Anthony J. Apostoli ${ }^{3}$, Kevin R. Brown ${ }^{4}$, Joshua Paterson ${ }^{3}$, Natalie Stickle ${ }^{3}$, Michael Robinette ${ }^{3}$, Neil Fleshner ${ }^{3}$, Robert J. Hamilton ${ }^{3}$, Girish Kulkarni ${ }^{3}$, Alexandre Zlotta ${ }^{3}$, Andrew Evans ${ }^{5}$, Antonio Finelli ${ }^{3}$, Jason Moffat ${ }^{4}$, Michael A. S. Jewett ${ }^{3}$ and Laurie Ailles ${ }^{1,3^{*}}$ (D)

\begin{abstract}
Background: Patients with clear cell renal cell carcinoma (ccRCC) have few therapeutic options, as ccRCC is unresponsive to chemotherapy and is highly resistant to radiation. Recently targeted therapies have extended progression-free survival, but responses are variable and no significant overall survival benefit has been achieved. Commercial ccRCC cell lines are often used as model systems to develop novel therapeutic approaches, but these do not accurately recapitulate primary ccRCC tumors at the genomic and transcriptional levels. Furthermore, ccRCC exhibits significant intertumor genetic heterogeneity, and the limited cell lines available fail to represent this aspect of ccRCC. Our objective was to generate accurate preclinical in vitro models of $c C R C C$ using tumor tissues from ccRCC patients. Methods: ccRCC primary single cell suspensions were cultured in fetal bovine serum (FBS)-containing media or defined serum-free media. Established cultures were characterized by genomic verification of mutations present in the primary tumors, expression of renal epithelial markers, and transcriptional profiling.

Results: The apparent efficiency of primary cell culture establishment was high in both culture conditions, but genotyping revealed that the majority of cultures contained normal, not cancer cells. ccRCC characteristically shows biallelic loss of the von Hippel Lindau (VHL) gene, leading to accumulation of hypoxia-inducible factor (HIF) and expression of HIF target genes. Purification of cells based on expression of carbonic anhydrase IX (CA9), a cell surface HIF target, followed by culture in FBS enabled establishment of ccRCC cell cultures with an efficiency of $>80 \%$. Culture in serum-free conditions selected for growth of normal renal proximal tubule epithelial cells. Transcriptional profiling of ccRCC and matched normal cell cultures identified up- and down-regulated networks in ccRCC and comparison to The Cancer Genome Atlas confirmed the clinical validity of our cell cultures.
\end{abstract}

Conclusions: The ability to establish primary cultures of cCRCC cells and matched normal kidney epithelial cells from almost every patient provides a resource for future development of novel therapies and personalized medicine for cCRCC patients.

Keywords: Clear cell renal cell carcinoma, In vitro models, Primary cell culture, Renal cancer, VHL

\footnotetext{
* Correspondence: lailles@uhnresearch.ca

'Department of Medical Biophysics, University of Toronto, Toronto, ON,

Canada

${ }^{3}$ Princess Margaret Cancer Centre, University Health Network, Toronto, ON,

Canada

Full list of author information is available at the end of the article
} 


\section{Background}

Renal cell carcinoma (RCC) is dominated by the clear cell subtype (ccRCC), which makes up $70 \%$ of all RCC and has a poor prognosis [1]. Biallelic loss or inactivation of the von Hippel Lindau ( $V H L$ ) gene via mutation, deletion or promoter methylation occurs in up to $91 \%$ of sporadic ccRCC [2] and drives a strong pro-survival and angiogenic program due to downstream hypoxiainducible factor (HIF) accumulation [3].

Cancer cell lines are used extensively to characterize novel anti-cancer therapeutics, but such studies have translated poorly from preclinical studies into clinically useful drugs. Genome-wide analysis shows that ccRCC cell lines have many more copy number alterations than primary ccRCC tissues [4], and transcriptional profiles of cell lines cluster separately from primary tumors [5]. In addition, ccRCC exhibits significant intertumor genetic heterogeneity $[6,7]$ and the limited cell lines available fail to represent this aspect of ccRCC. A lack of patientmatched normal cells further limits research due to the consequent lack of appropriate controls for experiments and drug screening efforts.

Recently researchers have developed methods for generation of primary tumor-derived cultures such as sphereforming or adherent cells from brain tumors $[8,9]$ or 3-D organoids from colorectal cancers [10]. These primary cultures are amenable to high-throughput assays and other manipulations while simultaneously representing more accurate preclinical models of the tumors from which they are derived. We describe a protocol for efficient generation of primary ccRCC and patient-matched normal kidney epithelial cell cultures from ccRCC tissue specimens, providing significant opportunities for development of personalized medicine approaches for ccRCC patients.

\section{Materials and methods}

\section{Tumor collection and processing}

ccRCC samples were obtained from the University Health Network (UHN) and the Cooperative Health Tissue Network from patients providing written consent under UHN Research Ethics Board approval, protocol \#09-0828-T (Additional file 1: Table S1). ccRCC tumor tissues were procured within $2-24$ h of excision (CHTN samples were shipped overnight from various sites in the United States). Tissue was finely minced using a scalpel, then incubated in a 5 to $10 \mathrm{~mL}$ volume of $1 \times$ Collagenase/ Hyaluronidase and 125 Units/mL DNase (Stem Cell Technologies) with frequent pipetting at $37{ }^{\circ} \mathrm{C}$ for two hours. Contaminating red blood cells were lysed with ammonium-chloride/potassium (ACK) lysing buffer (Gibco) and remaining undissociated tissue and cell clumps were filtered out using $70 \mu \mathrm{m}$ nylon mesh. Dissociated cells were stained with trypan blue, viable cells were counted and cells were either frozen in $90 \%$ fetal bovine serum (FBS)/10 \% dimethylsulfoxide or placed into culture.

\section{Cell culture}

Cell suspensions were cultured in Iscove's Modified Dulbecco's Medium (IMDM) with 10 \% FBS or defined serum-free media (DSFM). DSFM contained DMEM/ F12 + Glutamax, 1× B27 supplement (Gibco), 1× nonessential amino acids (Sigma-Aldrich), $1 \times$ Lipid Mixture 1 (Sigma-Aldrich), $4 \mu \mathrm{g} / \mathrm{mL}$ Heparin, $1 \mathrm{mM} \mathrm{N}$-acetyl cysteine (Sigma-Aldrich), $10 \mathrm{mM}$ HEPES, $10 \mathrm{ng} / \mathrm{mL}$ EGF (Invitrogen), and $10 \mathrm{ng} / \mathrm{mL}$ bFGF (Invitrogen). Both culture conditions included 100 Units $/ \mathrm{mL}$ penicillin, and $100 \mu \mathrm{g} / \mathrm{mL}$ streptomycin. 786-0 and A-498 cells were cultured in IMDM with $10 \%$ FBS, penicillin and streptomycin. All cultured cells were plated at a density of at least 5000 cells $/ \mathrm{cm}^{2}$ in flasks coated with rat tail collagen type IV $\left(5 \mu \mathrm{g} / \mathrm{cm}^{2}\right.$; BD Biosciences $)$ and incubated at $37{ }^{\circ} \mathrm{C}$, in $5 \% \mathrm{CO}_{2}, 2 \% \mathrm{O}_{2}$. Cell culture media was replaced every three to four days and cultures were passaged at confluence with $0.25 \%$ Trypsin (Wisent) and split between 1:2 and 1:5 depending on growth rate. Cell cultures were monitored for Mycoplasma infection (Mycoalert, Lonza) and cell culture identity verification by short tandem repeat profiling (AmpFLSTR ${ }^{\oplus}$ Identifiler $^{\oplus}$ ).

To determine doubling times, primary cell cultures were seeded in collagen-coated 96-well plates in IMDM/ $10 \%$ FBS at 2500 and 5000 cells/well (6 technical replicates each). 786-0 cells were seeded at a density of 300 cells/well. Plates were incubated in an IncuCyte ZOOM incubator and 4 images/well were taken at each time point. Growth curves based on cell confluence were compiled using IncuCyte ZOOM software from which estimates of doubling times were obtained.

\section{$V H L$ sequencing}

DNA was extracted using the Qiagen QIAamp DNA Mini kit. PCR for $V H L$ was performed using primer sequences and melting temperatures in Additional file 2: Table S2 and sequenced by Sanger sequencing. Mutations were identified using FinchTV software.

\section{Flow cytometry}

Cells were suspended in Hank's balanced salt solution with $2 \%$ FBS, blocked with $20 \mu \mathrm{g} / \mathrm{ml}$ mouse IgG on ice for $10 \mathrm{~min}$, then incubated on ice with anti-CD31-PECy7 (1:100; BD Biosciences), anti-CD45-PECy7 (1:100; BD Biosciences) and anti-CA9-PE (Clone 303123, 1:10; R\&D Biosystems) for $30 \mathrm{~min}$, washed, and resuspended in Hank's + $2 \%$ FBS with $1 \mu \mathrm{g} / \mathrm{ml}$ 4',6-diamidino2-phenylindole (DAPI). Viable (i.e. DAPI-negative) CD45/ CD31-negative cells were sorted into $\mathrm{CA}^{+}$and $\mathrm{CA}^{-}$populations using a BD FACSAriaII cell sorter. 


\section{Immunohistochemistry}

Adherent cell lines were grown in chamber slides to 50$90 \%$ confluence, washed in PBS, fixed in $4 \%$ paraformaldehyde for $15 \mathrm{~min}$ at $4{ }^{\circ} \mathrm{C}$, and subsequently washed and permeabilized in PBS with $0.1 \%$ Tween. Cells were then blocked with $0.5 \%$ BSA, $5 \%$ goat serum and $0.3 \%$ hydrogen peroxide, incubated with primary antibody for $30 \mathrm{~min}$ at room temperature, washed, and incubated with a biotinylated goat anti-rabbit or goat anti-mouse secondary antibody, as appropriate, at 1:1000 for $30 \mathrm{~min}$ at room temperature. Cells were again washed, incubated with 1:1000 streptavidin-HRP (BD Biosciences) for $30 \mathrm{~min}$ at room temperature, washed again, and incubated with 3,3'-diaminobenzidine (DAB) for 5 to $10 \mathrm{~min}$, as directed by the manufacturer (NovaRED Peroxidase Substrate Kit; Vector Laboratories), counterstained with hematoxylin, dehydrated, and coverslipped with histomount. Antibodies and dilutions were as follows: Pan-Cytokeratin, 1:100 (AbCAM); PAX-8, 1:500 (Protein Tech Group); Alkaline Phosphatase, 1:50 (Millipore); Aquaporin1, 1:100 (Abcam); E-Cadherin, 1:100 (Cell Signaling).

\section{Tumorigenicity in mice}

One million VHLmut cells were re-suspended in 1:1 PBS/ standard growth factor Matrigel (BD Biosciences) and injected under the renal capsule of male NOD/SCID/ IL2 $\mathrm{R}^{-/-}$mice. 5 mice were injected with each cell line. Animal experimentation followed protocols approved by the University Health Network Animal Care Committee. After 10 weeks, mice were euthanized and tumors were harvested, fixed in formalin, paraffin-embedded and subjected to hematoxylin and eosin staining to assess histology.

\section{Single Nucleotide Polymorphism (SNP) arrays}

Genomic DNA was applied to Illumina Human Omni Express-12 or Omni2.5-8 SNP arrays, hybridized as instructed by the manufacturer, and scanned on the iScan Reader (Illumina). SNP Array data was analyzed with Nexus software using the SNP-FASST2 segmentation algorithm. Probe sets were centered to the median for all samples. Linear systematic correction was applied as follows: The bias values, including percent GC content and fragment length, were used to create a linear model whose parameters were estimated using the least squares method. The estimate was then subtracted from the probe Log2Ratio to obtain the corrected probe values. A minimum difference threshold of $25 \%$ and a $p$-value cutoff of 0.05 were used.

\section{Transcriptional profiling}

mRNA was extracted from snap-frozen tumor tissue and from $V H L$ mut and $V H L w t$ cultures that were expanded in $10 \%$ FBS conditions at passages 2 to 5 . mRNA was isolated using a Qiagen RNeasy Kit and Poly-A enriched mRNA libraries were prepared following the Illumina TruSeq RNA Sample Preparation Kit v2 protocol. Libraries were sized on an Agilent Bioanalyzer, and their concentrations were validated by qPCR. Equimolar amounts of the eighteen different libraries were pooled, and subjected to 51 cycles of single-read sequencing on an Illumina HiSeq 2500 using Illumina V4 chemistry and reagents. The mean number of reads/sample was $40.4 \mathrm{M}$ (min. 34.6 M, $\max 52.5 \mathrm{M}$ ). Reads were aligned to the GRCh37 reference human genome, using Gencode V19 transcript models. Alignment was performed with Tophat (v2.0.13), using default parameters and with the Gencode V19 transcriptome index supplied. The median percentage of aligned reads was $95.8 \%(\min 91.4 \%$, max $96.8 \%)$. Gene expression levels were estimated with Cufflinks (v.2.0.2) [11], using default parameters and the Gencode V19 GTF file. All resulting cufflinks output files were merged using a bespoke script written in $\mathrm{R}$ (v.3.1.3). For differential expression analysis, a read count matrix was generated with the Bioconductor package 'GenomicFeatures' (v1.18.7), using the UCSC hg19 "knownGene" transcripts table. Differential expression was determined using limma (v3.22.7).

\section{Gene set enrichment analysis}

Three GSEA analyses were performed using the RNAseq data: 1) Using the GSEA v2.2.1 PrerankedTool the VHLmut and VHLwt signatures (Fig. 5a) were queried against a ranked gene list of TCGA RNAseq data, ranked based on adjusted $p$-values of ccRCC vs. adjacent normal tissue [7]; 2) A gene set database obtained from baderlab.org/GeneSets, which contains 14,082 gene sets from KEGG, MSigDB, Reactome, and GO was queried against a ranked list of the VHLmut vs. VHLwt RNAseq data, ranked based on adjusted $p$-value; 3) MSigDB Collection C5, consisting of 1454 GO gene sets was queried against the patient tumor vs. VHLmut cells ranked gene list (again ranked based on adjusted $p$-value). For the latter two analyses, the outputs from GSEA were imported into Cytoscape v3.2.0 and visualized using the Enrichment Map plugin.

\section{Results}

Most unselected ccRCC cultures are not cancer cells

CcRCC specimens were processed into primary single cell suspensions, cultured in $10 \%$ FBS or defined serum-free media (DSFM; see Methods) and incubated in $2 \%$ oxygen to improve cell growth and avoid DNA damage [12, 13]. Cells with an epithelial morphology that could be passaged at least 4 times were consistently obtained (56.4 \% in DSFM and $71.8 \%$ in FBS; $n=39$ ). Eight primary cultures with matched primary tumors and adjacent normal tissues were genotyped using single nucleotide 
polymorphism (SNP) arrays and, surprisingly, 6 out of 8 cultures established in FBS and all cultures in DSFM had a normal genotype (Additional file 10: Figure S1A). Sequencing of $V H L$ in primary tumors and cultures verified a patient tumor-matching VHL mutation in RCC22 cells grown in FBS (Additional file 10: Figure S1B), while the remaining lines did not recapitulate the patients' tumor VHL mutations.

To distinguish cancer vs. normal cells in subsequent experiments, we sequenced the $V H L$ gene in a cohort of patients for whom cryopreserved viable single cell suspensions were available. Once patients with sequencedetectable mutations were identified, the cells were thawed and cultured as before. Seven out of seven DSFM cultures were $V H L$-wild-type (VHLwt) and only one of seven cases grown in FBS (RCC130) was VHLmutant (VHLmut). Another FBS culture, RCC243 contained a mixture of $V H L$ mut and $V H L w t$ cells at passage two (Fig. 1a).

\section{Purification of CA9-expressing cells facilitates establish- ment of ccRCC cultures}

$V H L$ loss results in HIF accumulation and activation of HIF target genes including carbonic anhydrase IX (CA9), which is constitutively upregulated in $V H L$-mutant cells and acts as a diagnostic biomarker in this disease [14, 15].

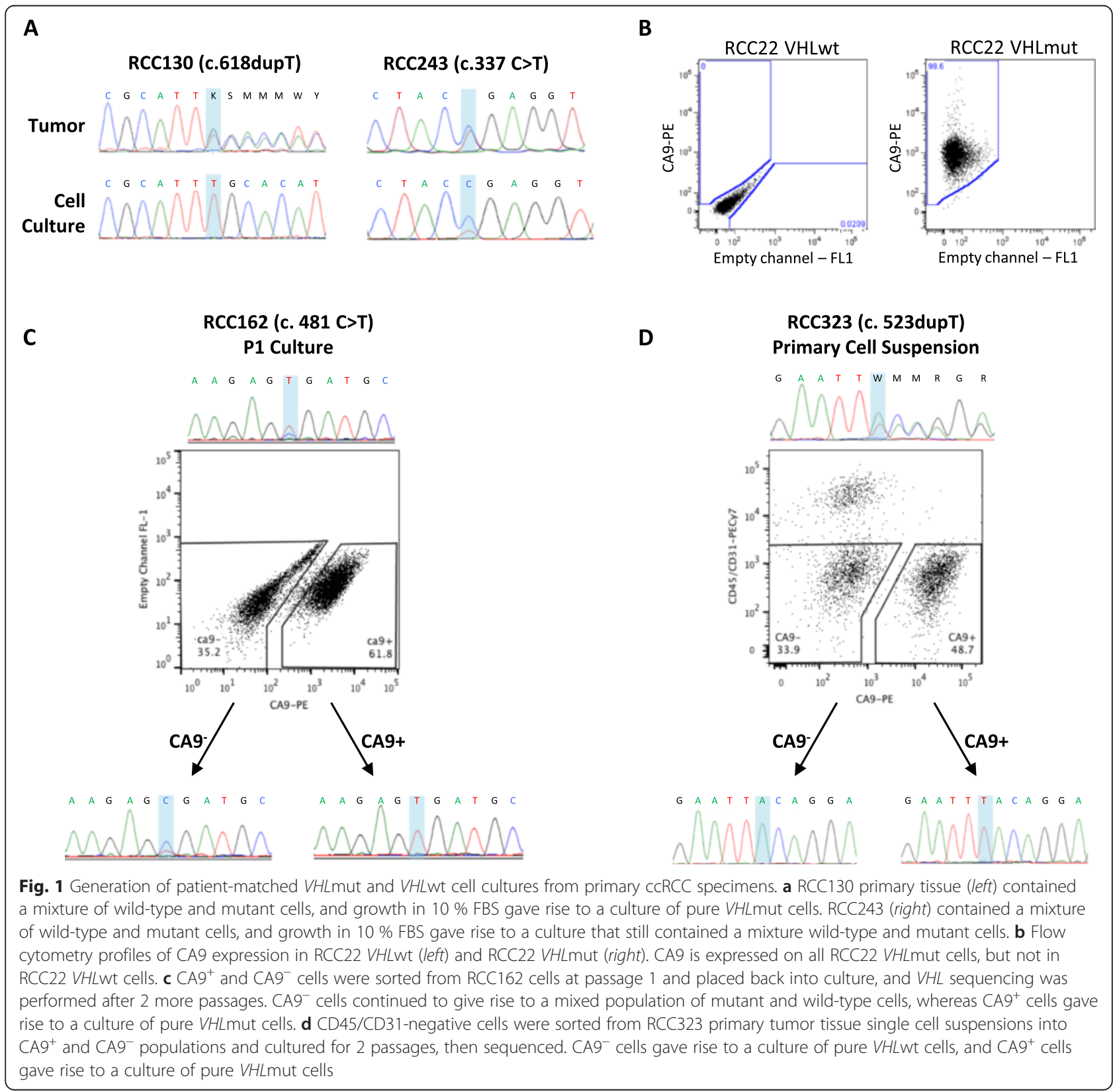


Supporting this, RCC22 VHLmut cells expressed CA9, while RCC22 VHLwt cells did not (Fig. 1b). To determine whether this known ccRCC cell surface marker could be used to select ccRCC cells present in mixtures of cancer and normal cells, we purified $\mathrm{CA}^{+}$and $\mathrm{CA}^{-}$cells from cryopreserved primary single cell suspensions or early passage $10 \%$ FBS cultures using fluorescence-activated cell sorting, and (re)cultured them in $10 \%$ FBS (Fig. 1c, d). Cells were passaged twice before re-sequencing the $V H L$ gene. The efficiency of $V H L$ mut cell culture establishment increased to $37.5 \%$ (6 out of 16 attempts) upon sorting of $\mathrm{CA} 9^{+}$cells from early passage cultures, and to $84.6 \%$ (11 out of 13 attempts) upon sorting of $\mathrm{CA}^{+}$cells from primary cell suspensions (Table 1 ). The $\mathrm{CA}^{-}$population gave rise to $V H L w t$ cultures $75 \%$ of the time vs. $66.7 \%$ of the time in early passage vs. primary cell suspensions, respectively. We also established pure VHLwt cells $70.6 \%$ of the time when primary cell suspensions were plated directly into DSFM without sorting. In 4 cases where VHLwt cultures were not established by plating directly in DSFM, they were established from purified $\mathrm{CA}^{-}$cells. Once established, VHLwt cells grew efficiently in both FBS and
DSFM conditions, and thus were transitioned to FBS conditions once verified to be VHLwt by Sanger sequencing. By contrast, VHLmut lines proliferated only in FBS. VHLmut and VHLwt cells could not be distinguished based on morphology (Additional file 10: Figure S2). Resequencing at later passages (up to 20) verified that the VHL status of both mutant and wild-type cultures was maintained. Overall, we have successfully established 17 VHLmut ccRCC cell cultures, of which 16 have patientmatched VHLwt cell cultures (Additional file 3: Table S3).

VHLwt cell cultures are renal proximal tubule epithelial cells We next performed immunohistochemistry for renal epithelial markers in VHLwt and VHLmut cultures. All were positive for pan-Cytokeratin and PAX8 (Fig. 2), a transcription factor expressed only in epithelial cells of the adult kidney, in $98 \%$ of ccRCCs [16], and in the thyroid gland and Müllerian duct derived tissues, but not other tissues [17]. These results support the renal epithelial origin of the VHLmut and VHLwt cultures. VHLwt cells are also positive for proximal tubule markers Alkaline Phosphatase [18] and Aquaporin1 [19]

Table 1 Efficiency of VHLmut and VHLwt primary culture establishment upon isolation of CA9+ and CA9- cells from early passage cultures or primary single cell suspensions

\begin{tabular}{|c|c|c|c|c|c|c|}
\hline \multirow[b]{2}{*}{ Tumor ID } & \multicolumn{3}{|c|}{ Cells sorted at P0 to P2 } & \multicolumn{3}{|c|}{ Cells sorted from primary single cell suspension } \\
\hline & Passage & CA9+ & CA9- & CA9+ & CA9- & Unsorted (DSFM) \\
\hline $118^{c}$ & 0 & pure $T$ & $50 / 50^{a}$ & pure $T$ & $50 / 50^{a}$ & no line \\
\hline $137^{c}$ & 0 & mixture & no line & pure $T$ & pure $\mathrm{N}$ & no line \\
\hline $138^{c}$ & 0 & mixture & no line & pure $T$ & pure $\mathrm{N}$ & no line \\
\hline $149^{c}$ & & ND & ND & pure $T$ & pure $\mathrm{N}$ & pure $\mathrm{N}$ \\
\hline $162^{c}$ & 0 & pure $T$ & $50 / 50^{a}$ & ND & ND & $50 / 50^{a}$ \\
\hline $171^{c}$ & 2 & mixture & pure $\mathrm{N}$ & pure $T$ & pure $\mathrm{N}$ & ND \\
\hline 183 & 1 & pure $\mathrm{N}$ & pure $\mathrm{N}$ & ND & ND & pure N \\
\hline 200 & & ND & ND & mixture & pure N & no line \\
\hline $222^{c}$ & 0 & mixture & pure $\mathrm{N}$ & pure $T$ & pure N & pure N \\
\hline $243^{c}$ & 2 & pure $T$ & mixture & ND & ND & pure N \\
\hline 267 & 0 & pure $\mathrm{N}$ & pure $\mathrm{N}$ & ND & ND & pure N \\
\hline $271^{c}$ & 0 & pure $T$ & mixture & pure $T$ & mixture & pure N \\
\hline $291^{c}$ & 0 & pure $\mathrm{N}$ & pure $\mathrm{N}$ & pure $T$ & no line & ND \\
\hline 294 & 0 & mixture & pure $\mathrm{N}$ & no line & ND & pure $N$ \\
\hline $323^{c}$ & 0 & pure $T$ & pure $\mathrm{N}$ & pure $T$ & mixture & pure N \\
\hline $364^{b}$ & & ND & ND & pure $T$ & no line & no line \\
\hline 373 & 0 & mixture & pure N & ND & ND & pure N \\
\hline $400^{c}$ & 0 & pure $\mathrm{N}$ & pure $\mathrm{N}$ & pure $T$ & pure $\mathrm{N}$ & pure N \\
\hline \multirow[t]{2}{*}{$407^{c}$} & 0 & pure $T$ & pure $\mathrm{N}$ & ND & ND & pure N \\
\hline & & $\begin{array}{l}6 \text { of } 16 \text { ccRCC } \\
\text { cultures ( } 37.5 \%)\end{array}$ & $\begin{array}{l}12 \text { of } 16 \text { normal } \\
\text { cultures (75\%) }\end{array}$ & $\begin{array}{l}11 \text { of } 13 \text { ccRCC } \\
\text { cultures (84.6\%) }\end{array}$ & $\begin{array}{l}8 \text { of } 12 \text { normal } \\
\text { cultures (66.7 \%) }\end{array}$ & $\begin{array}{l}12 \text { of } 17 \text { normal } \\
\text { cultures (70.6\%) }\end{array}$ \\
\hline
\end{tabular}

$T$ tumor, $N$ normal, ND not done

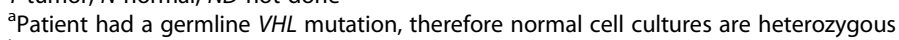

${ }^{b}$ VHLmut cell line only was generated, $n=1$

${ }^{c}$ VHLmut and VHLwt pairs were generated, $n=13$ 


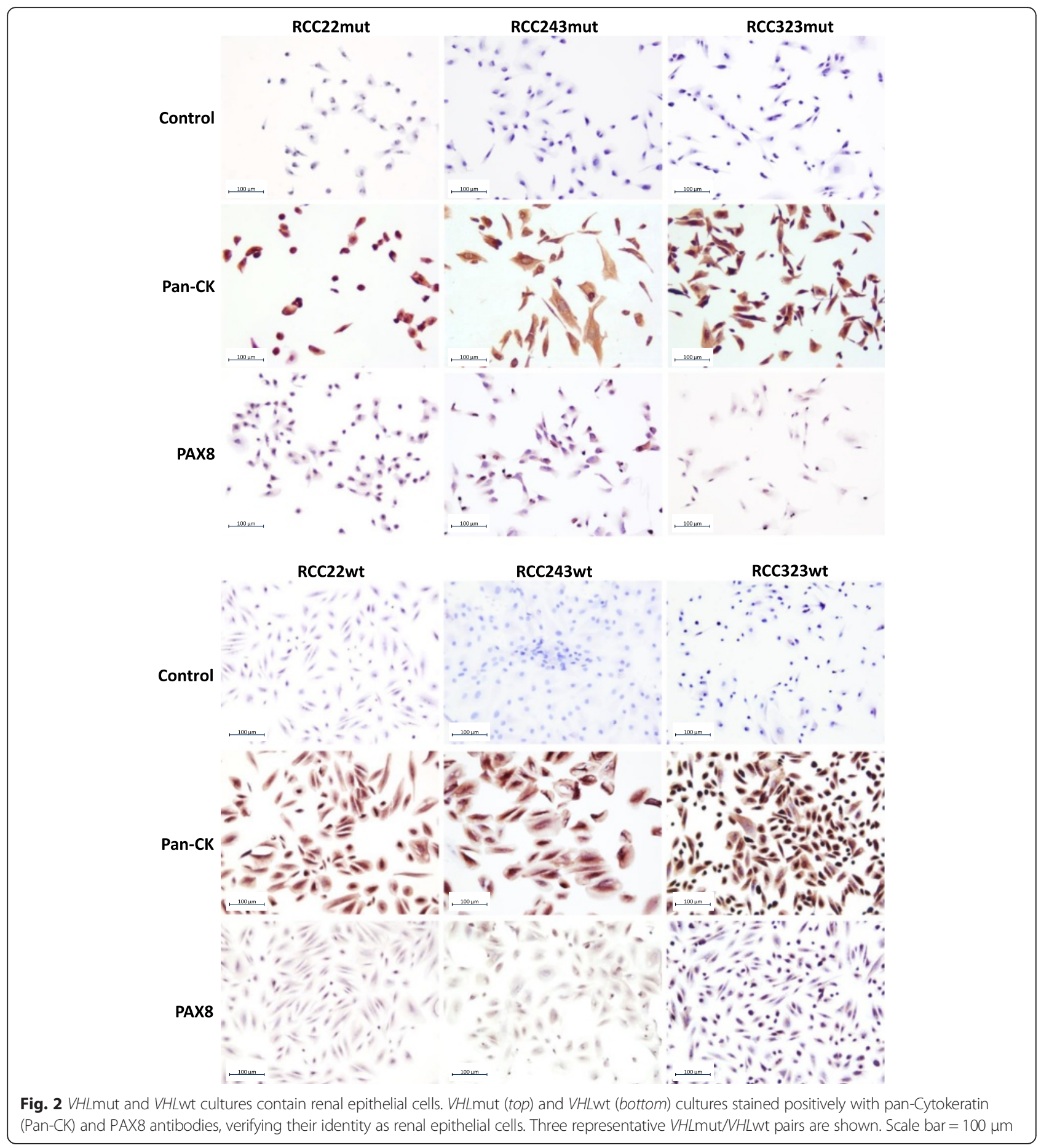

(Fig. 3a) and negative for distal tubule markers ECadherin and Calbindin1 (Additional file 10: Figure S3). Furthermore, analysis of the expression of proximal and distal tubule markers in RNAseq data generated from 6 pairs of VHLmut and VHLwt cells indicates consistently higher expression of proximal tubule markers in $V H L w t$ cells (Fig. 3b), supporting their identity as proximal tubule epithelial cells. VHLmut cells also express proximal tubule markers, as expected [20].

\section{Growth characteristics of $V H L$ mut and $V H L$ wt cells}

To assess growth kinetics of VHLmut and VHLwt cultures, growth curves were generated using an Incucyte ZOOM live cell imaging apparatus. The doubling times of 


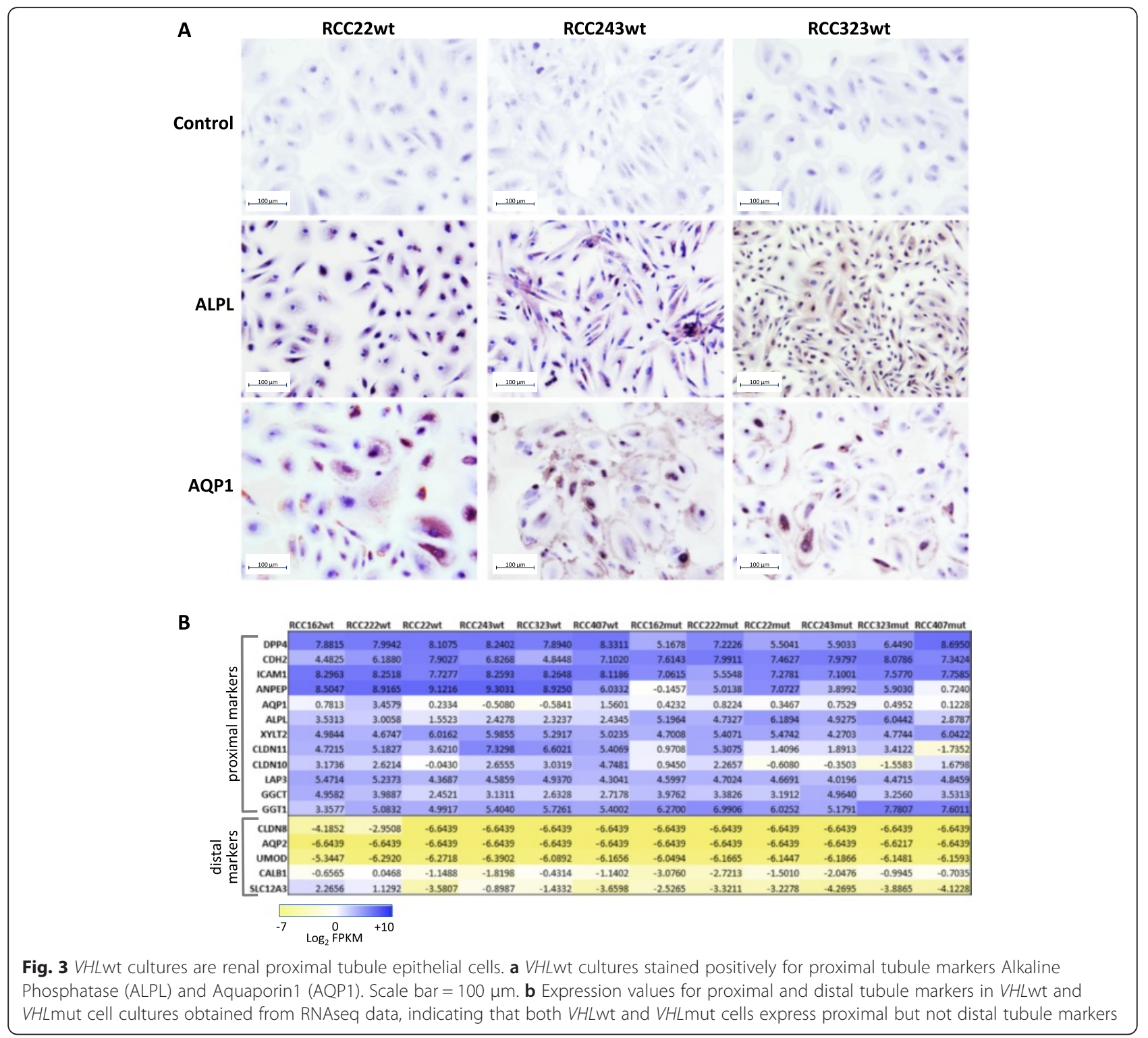

7 VHLmut cultures averaged $130 \mathrm{~h}$ (range 44 to 219; Additional file 4: Table S4). In contrast to VHLmut cultures, the commercial cell line 786-0 had a doubling time of $16 \mathrm{~h}$. These 7 cultures have been passaged from 12 to 20 times and have not yet shown signs of senescence. In contrast, the growth of VHLwt cultures slows between passages 6 and 12, though significant expansion and cryopreservation at early passage is possible. To assess tumorigenicity, 1 million VHLmut cells were injected under the renal capsule of five NOD/SCID/IL2R ${ }^{-/-}$mice and 2 out of 4 VHLmut cultures consistently generated tumor xenografts with ccRCC histology within 10 weeks (Additional file 10: Figure S4).

\section{Molecular analysis of VHLmut and VHLwt primary cultures} To assess genotype stability in vitro, we performed SNP arrays on three VHLmut cultures that had reached 20 passages, two matched earlier passage VHLwt cultures, plus their matched primary tumors and adjacent normal tissues. Two commercially available ccRCC cell lines, 786-0 and A-498 were also analyzed (Fig. 4). VHLwt cell cultures do not exhibit gross genomic abnormalities. VHLmut cultures match the copy number alterations (CNAs) of their paired parental tumors, and display a few additional alterations that were not obvious in primary tumors: RCC22mut and RCC243mut have gain of chromosome 7, RCC243mut also has loss of chromosome 4, and RCC364mut has 2 deletions, one in chromosome 8 and one in chromosome 9. In comparison, 786-0 and A-498 had considerably more CNAs than primary ccRCCs.

We performed RNAseq on $6 \mathrm{VHLmut} / V H L$ wt cell culture pairs grown in $10 \% \mathrm{FBS}$ at passage 2 to 5 , as well as RNA extracted from the matched primary tumor 


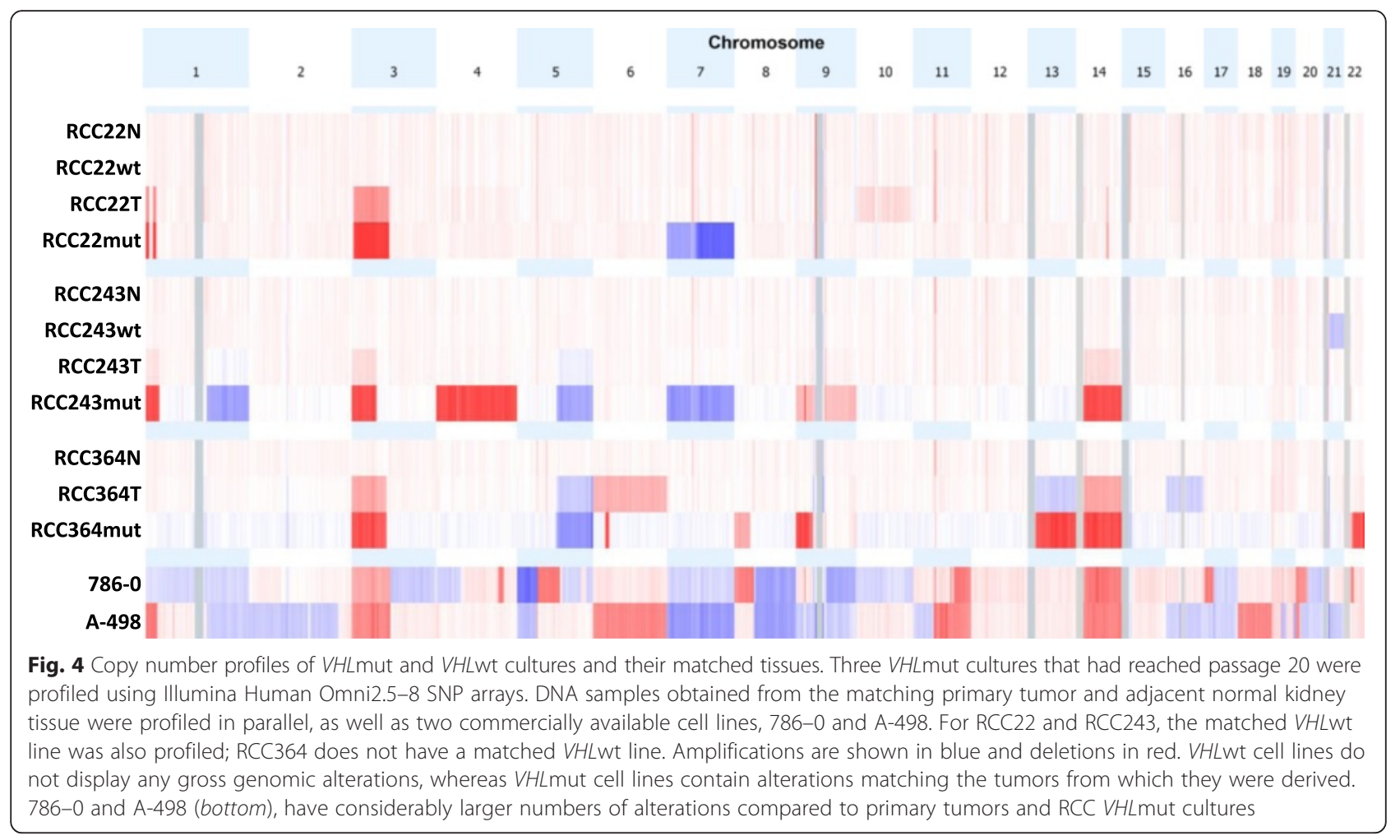

tissues. RNAseq data has been deposited in NCBI's Gene Expression Omnibus [21] and are accessible through GEO Series accession number GSE74958. Upon unsupervised clustering of gene expression profiles the tumor tissues clustered discretely from the cultured cells, and the VHLmut and VHLwt cultures formed discrete subclusters, indicating distinct expression profiles within each sample type (Additional file 10: Figure S5). 593 differentially expressed protein-coding genes (cut-off of 2 -fold and adjusted $p$-value $\leq 0.01)$ were identified between $V H L$ mut and VHLwt cell cultures (Fig. 5a). Genes differentially expressed in $V H L$ mut cells included hypoxia response genes and genes related to metabolism, as expected (Additional file 5: Table S5, Additional file 10: Figure S6). Gene set enrichment analysis (GSEA) of the VHLmut and VHLwt gene signatures against RNAseq data from patient-matched primary tumor and adjacent normal tissues generated by The Cancer Genome Atlas (TCGA) [7] showed significant enrichment of the VHLmut signature in ccRCC tumor tissues, and of the VHLwt signature in normal adjacent kidney tissues, respectively (Fig. 5b).

To gain a better understanding of differentially expressed networks in VHLmut vs. VHLwt cells, we also performed GSEA of a compiled database of gene sets relating to biological processes, molecular functions and pathways [22] against a ranked gene list of our entire expression dataset [23]. Results were visualized using Cytoscape with the Enrichment Map plugin [22]. Only a few networks were up-regulated in VHLmut cells, including glycolysis and electron transport, hypoxia/oxygen response, epigenetics/histone modification and bile acid and bile salt transport (Fig. 6, Additional file 6: Table S6). The top differentially expressed genes associated with each of these networks are listed in Additional file 7: Table S7. A larger number of pathways and networks were enriched in VHLwt cells, including cell-cell and cellmatrix interactions, focal adhesion and cytoskeleton organization, epithelial and endothelial differentiation, growth factor pathways such as TGF $\beta$ and TNF, glycosylation, and RNA processing and transport (Additional file 6: Table S6).

An analysis of differentially expressed genes between VHLmut cell cultures and the matched tumors from which they were derived revealed 4312 differentially expressed genes (cut-off 2 -fold and adjusted $p$-value $\leq 0.01$; Additional file 8: Table S8). Interestingly, there were many more genes lost in VHLmut cells as compared to primary tumors (2781) than gained (1531). As above, GSEA of gene ontology (GO) terms was performed using the ranked gene list of the primary tumor vs. VHLmut genes, and the results were again visualized using the Cytoscape Enrichment Map plugin (Additional file 10: Figure S7). Networks that were lost in VHLmut cultures consisted almost entirely of networks associated with immune responses, and mitochondrial respiration. The only network found to be gained in the VHLmut 


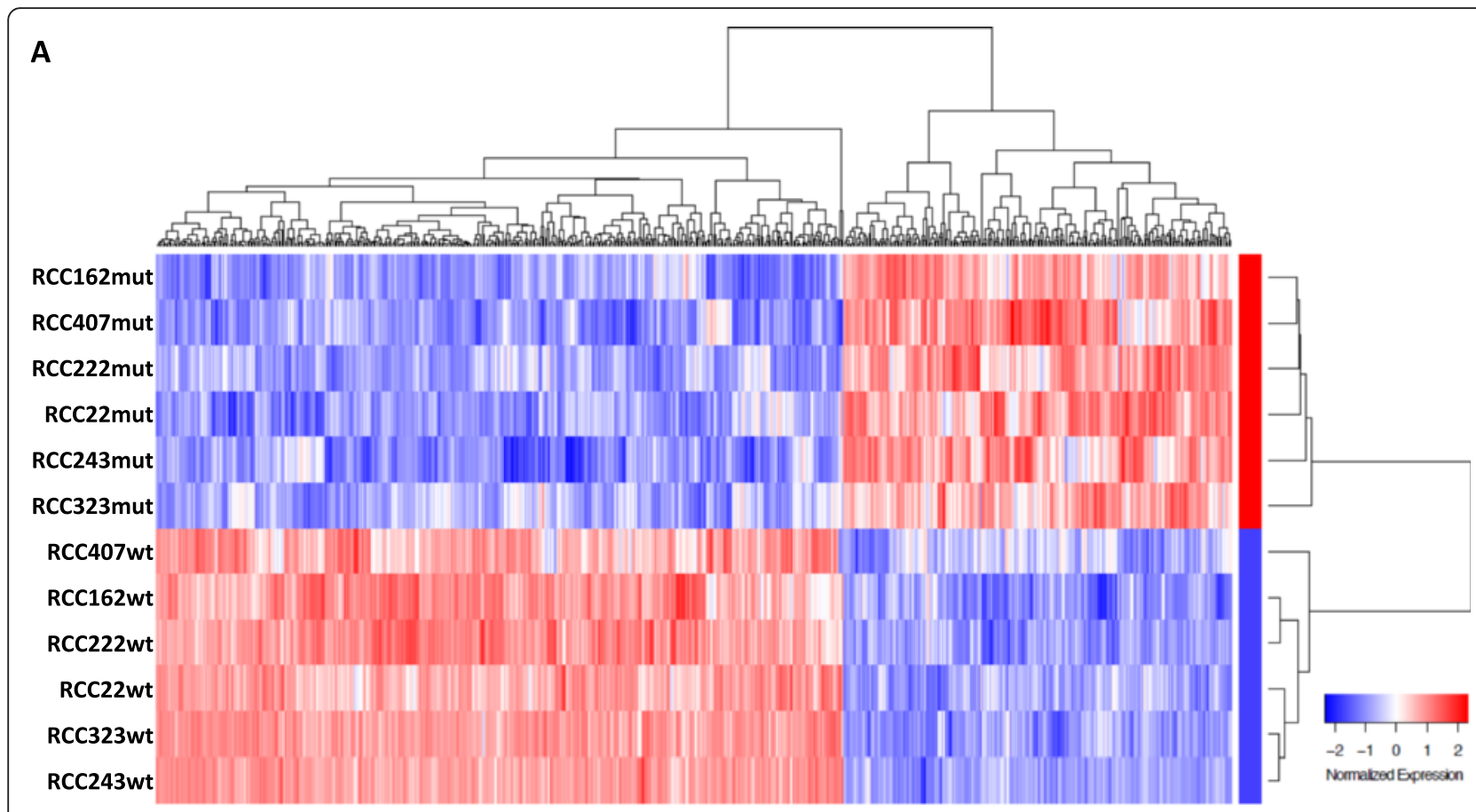

B
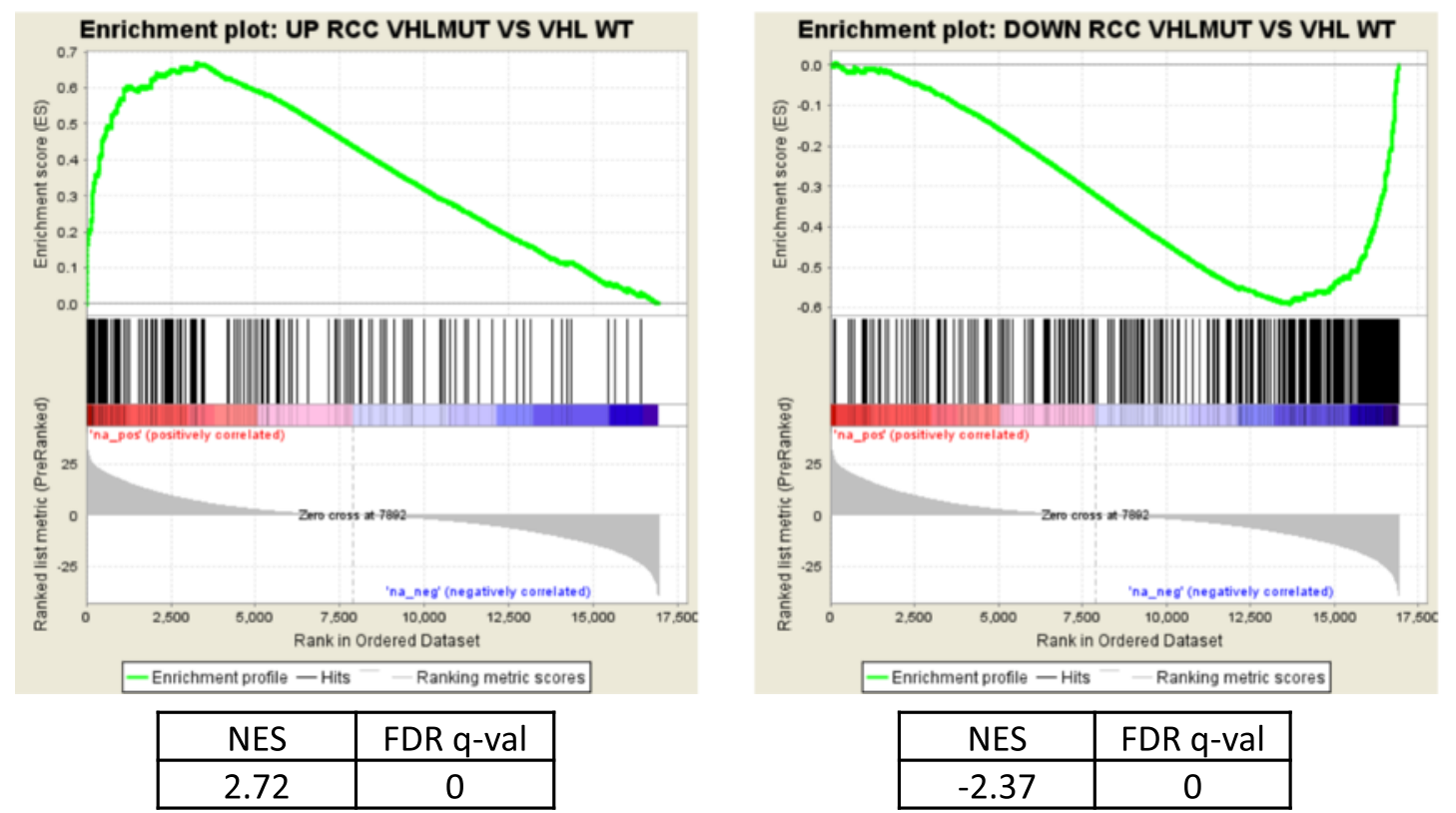

Fig. 5 Differentially expressed genes in VHLmut vs. VHLWt cells. a Heatmap showing the 593 differentially expressed protein-coding genes between VHLmut and VHLwt cells (cut-off of $p \leq 0.01$ and 2-fold change). b Gene set enrichment analysis (GSEA) plots of the 211 VHLmut-associated genes (left) and 382 VHLwt-associated genes (right) in the TCGA cCRCC dataset. NES = normalized enrichment score; FDR q-val = false discovery rate $q$ value. A gene set is considered significant with FDR $<0.25$

cultures as compared to the primary tumors was proliferation (Additional file 9: Table S9).

\section{Discussion}

Our finding that unselected cultures derived from primary ccRCC specimens contained predominantly genomically normal epithelial cells was surprising and highlights the importance of genotypic validation of newly established cultures in comparison to the patient tissues from which they are derived. Others have reported that normal cells out-compete malignant cells in primary cancer cultures $[10,24,25]$, possibly explaining the poor efficiency of cell 


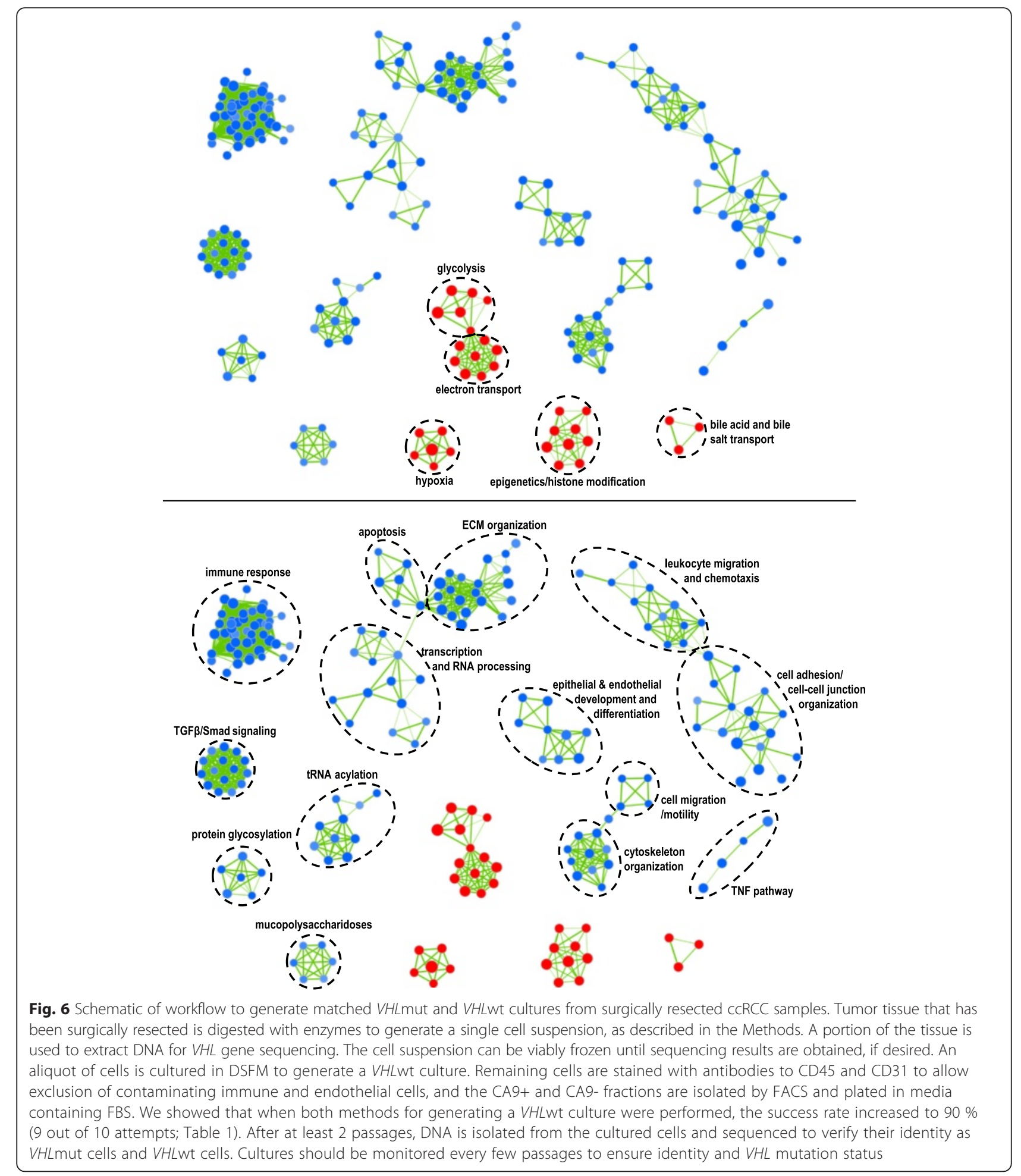

line derivation from most solid tumors [26] where lines can often be established, but cannot be maintained. Our protocol establishes accurate VHLmut ccRCC cultures that can be passaged at least 20 times. This method will allow researchers to avoid use of extensively passaged lines of uncertain provenance, instead enabling use of early passage, clinically relevant ccRCC cultures for basic studies.

The purification of ccRCC cells expressing CA9 increased both culture accuracy and efficiency substantially for samples bearing $V H L$ mutations. This method 
can be applied to any specimen yielding at least 1 million viable cells upon processing, thus one limitation is the inability to generate cultures from small specimens, such as biopsies. While not all ccRCC tumors have a detectable $V H L$ mutation, $V H L$ loss due to biallelic deletion or epigenetic silencing occurs in many of these patients [2]. While we have not formally tested CA9 sorting in these patients, our method is likely also applicable in these cases. Indeed, CA9 is expressed in the vast majority (94\%) of ccRCC patients [15].

Our results indicated that cultures established in DSFM were normal renal proximal tubule epithelial cells, the presumed cell of origin for ccRCC [1]. The outgrowth of normal epithelial cells was surprising given that these cells are not obviously present upon microscopic examination of tumor tissues, leading us to conclude that tumor tissues contain rare residual normal cells with a strong growth advantage over ccRCC cells in DSFM. These culture conditions are remarkably similar to conditions established decades ago for the culture of proximal tubule cells from normal kidneys [27]. Interestingly, our results indicate that DSFM culture conditions that support other cancers like glioblastoma multiforme, prostate cancer, and colorectal cancer [28] do not permit ccRCC cell growth; when we transferred VHLmut cultures from FBS to DSFM they failed to proliferate, suggesting the intriguing possibility that identification of essential growth factors for ccRCC cells could reveal novel therapeutic targets. Importantly, the differential growth requirements of VHLmut ccRCC cells and VHLwt normal proximal tubule epithelial cells can be exploited to consistently generate patient-matched normal cultures for virtually every cancer culture, even in the absence of adjacent normal tissue. While these cells senesce at passage 6 to 12, this could potentially be overcome by immortalization with a human telomerase reverse transcriptase ( $h T E R T)$ construct.

Primary VHLmut cultures had doubling times ranging from 44 to $>200 \mathrm{~h}$, in striking contrast to the 786-0 doubling time of $16 \mathrm{~h}$. This more accurately reflects the heterogeneity and growth kinetics observed in patients and primary xenografts. Cultures were readily established from tumors of varying stages and grades (Additional file 1: Table S1) suggesting no bias for success from more aggressive cancers. Two of four cultures tested to date generate xenografts with characteristic ccRCC clear cell histology. The failure of some cultures to initiate tumors in mice may be due to an insufficient cell dose, or to the eight to ten week incubation period. In our experience patient-derived xenografts initiated directly from primary tissues require four to six months to engraft [29], thus longer incubation times may be required. This would further indicate that our primary cultures are more reflective of patients' cancers than commercially available cell lines.
SNP array analyses indicated that, as shown by Beroukhim et al. [4], the cell lines 786-0 and A-498 have a large number of CNAs. In our two SNP array experiments we saw a single sample, RCC99 (Additional file 10: Figure S1) that also had substantial CNAs, but this is not typical of ccRCC, as seen in larger-scale genomic studies such as that of Beroukhim et al. [4] and the TCGA [7]. Thus while it is possible that cell lines such as 786-0 and A-498 were derived from such samples, the more likely explanation is that many genomic alterations are acquired during longterm passage in culture. At passage 20 our VHLmut cultures contained a small number of alterations that were not apparent in their parent tumors, but they did not have the extreme aneuploidy seen in commercially available ccRCC cell lines [4]. This is likely related to their relatively low passage number, and in part to their maintenance in a low oxygen environment, which has been found to increase plating efficiency and lifespan of cells in culture [12], as well as lead to less DNA damage and fewer stress responses [13]. The novel CNAs that were observed in VHLmut cultures compared to their matched primary tumors were concordant with common events in ccRCC such as trisomy 7 [30], suggesting that clones with these alterations may have been present at a subclonal level within the primary tumors, or that cultures were derived from a subclone that was not present in the portion of tumor used for DNA analysis due to regional genetic heterogeneity in ccRCC [31]. Future studies utilizing cultures derived from multiple biopsies per patient may provide valuable insights into biological differences between subclones. Alternatively, these alterations could have been acquired during passage, suggesting that despite our best efforts we did not entirely avoid the acquisition of genomic alterations during culture, and supporting the need to utilize in vitro models at early passage.

Transcriptional profiling identified differentially expressed genes between VHLmut and VHLwt cultures. Our VHLmut gene signature is highly enriched in patient ccRCC samples analyzed by the TCGA and transcriptional networks were identified that would be predicted as a consequence of $V H L$ loss: activation of the hypoxic response and increased glycolysis due to HIF stabilization. These results support the use of our VHLmut/VHLwt paired cultures as representative models of ccRCC biology. The observed increase in genes involved in electron transport/oxidative metabolism, which has been shown to be down regulated in other transcriptional analyses of ccRCC [32] was initially unexpected, however, some of the genes that are present in this network are in fact involved in negative regulation of electron transport; for example, the most significant gene in that network, NDUFA4L2 (see Additional file 7: Table S7) has been shown to be involved in lowering mitochondrial oxygen consumption and Complex I mitochondrial activity, causing a shift from 
mitochondrial respiration to anaerobic glycolysis [33]. Other genes in the network are associated with other metabolic processes such as adipogenesis and glycogen synthesis, in line with the fat and glycogen storage phenotype that is the hallmark of "clear cell" RCC [34]. In addition, recent findings suggest that as ccRCC cell lines adapt to in vitro culture they derive more of their metabolic demands from oxidative metabolism than directly isolated ex vivo cells [35]. We also noted a network of epigenetics-related nodes, concordant with recent findings that widespread deregulation of chromatin status occurs in ccRCC due to activation of hypoxia-related pathways,

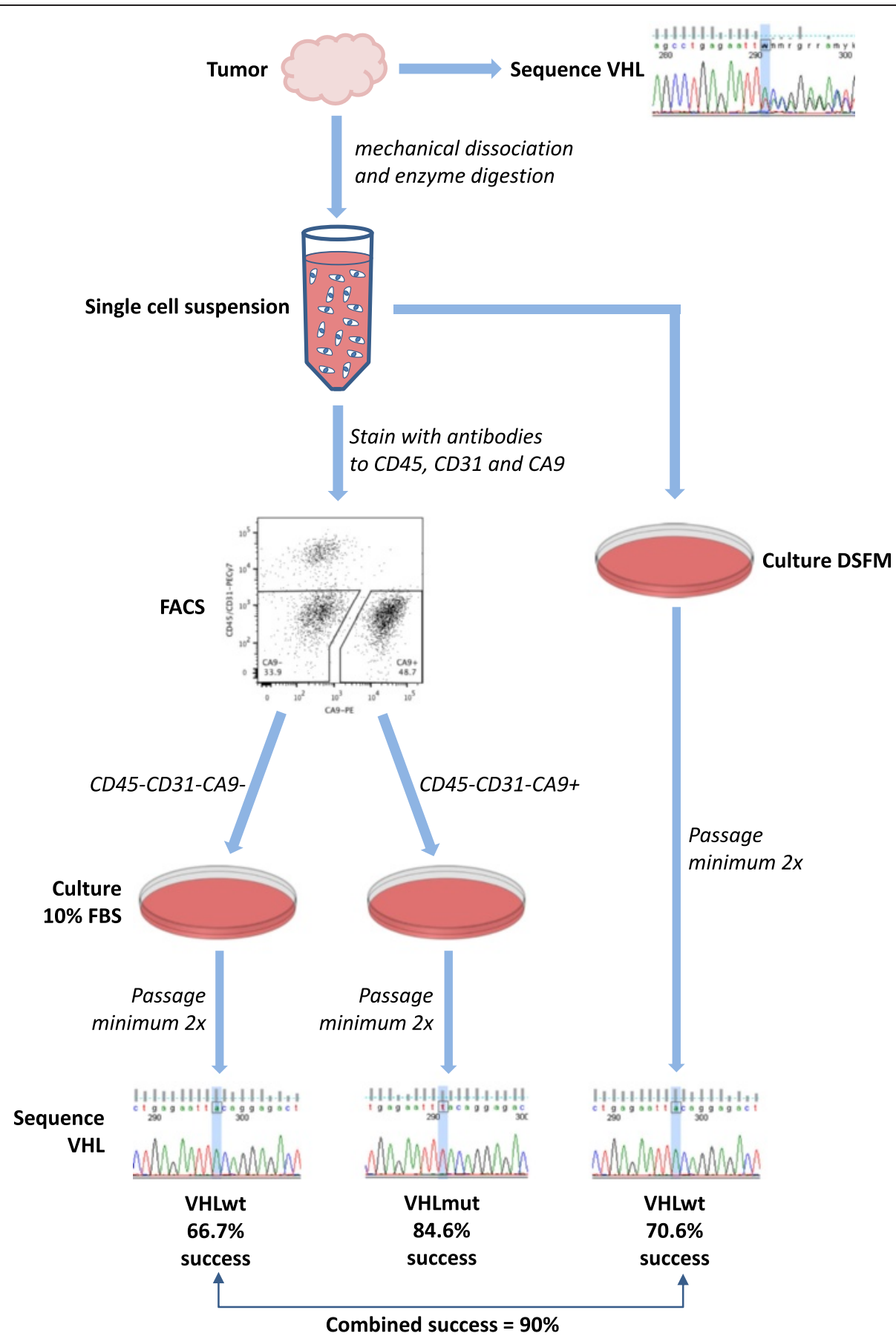

Fig. 7 Enrichment map of VHLmut vs. VHLwt gene expression profiles. To visualize networks and pathways differentially expressed between VHLmut and VHLWt cell cultures, we performed gene set enrichment analysis, and visualized the results using the Cytoscape Enrichment Map plugin, as described in the Methods. VHLmut related networks are shown in red (top) and VHLwt related networks are shown in blue (bottom) 
as well as mutations in epigenetic regulatory genes [6]. Our observation that many networks are downregulated, including transcription and RNA processing, is also consistent with observations that hypoxia induces a signature of chromatin modifications and global repression of transcription [36]. Additional pathways repressed in $V H L$ mut cells include functions related to normal epithelial biology and tissue homeostasis, such as cytoskeleton organization, cell-cell interactions, extracellular matrix organization and apoptosis, whose loss likely plays a significant role in the malignant behavior of ccRCC.

Comparison of transcriptional profiles between $V H L$ mut cells and their matched primary tumor specimens revealed $>4000$ differentially expressed genes. At first glance this suggests that the VHLmut cultures are not representative of the primary tumors from which they were derived at the transcriptional level. However, a deeper analysis of the differentially expressed genes in the tumor tissues revealed that these were related primarily to a wide range of immune functions, suggesting that the expression of these genes was lost due to the presence of large numbers of infiltrating immune cells in the tumor tissues that were not present in the cultures. Likewise, a higher expression of mitochondrial respirationassociated genes in the tumor tissue likely also reflects the presence of stromal cells within the tumor tissue that do not have VHL mutations and thus maintain normal levels of mitochondrial metabolism. Indeed, a recent study in which an algorithm was developed to estimate the fraction of stromal and immune cells in tumor samples from gene expression data [37] showed that, upon analysis of gene expression data sets from ten tumor types, ccRCC contained a particularly high level of immune signature expression that correlated with the tumor cellularity as assessed by DNA analysis. The predominant network upregulated in $V H L$ mut cultures compared to the matched primary tissues was proliferation, which is also not surprising given that the cultured cells are proliferating in response to culture conditions, whereas the proliferation index in ccRCC tumor tissues as defined by Ki67 staining is in general quite low (median $7.3 \%$ in one study of 176 patients) [38]. Thus overall, while a large number of differentially expressed genes were identified between tumor tissues and VHLmut cultures, the majority of these were related to the loss of immune cells in the cultures, and the stimulation of cell proliferation in vitro.

\section{Conclusions}

We have exploited the unique biology of ccRCC to develop a protocol for the reproducible and accurate generation of ccRCC and patient-matched normal proximal tubule epithelial cell cultures (Fig. 7). Transcriptional profiles recapitulate those of primary ccRCC tissues and verify the expression of pathways known to be key components of ccRCC cell biology. The high efficiency of cell culture establishment means that large numbers of cultures can be established from individual patients, allowing studies to be performed that take into consideration the genetic diversity of patients. The ability to generate patient-matched normal cultures from every patient provides a powerful tool for exploring molecular and functional differences between normal and cancer cells and provides ideal reagents for screening for cancer-specific compounds. Our protocol thus overcomes the severe limitations imposed by use of commercial cell lines, and provides a unique resource for the development of personalized therapeutic approaches in a disease that is in great need of novel therapies.

\section{Additional files}

Additional file 1: Table S1. Clinical characteristics of samples used to generate cell lines. (XLS $36 \mathrm{~kb}$ )

Additional file 2: Table S2. Primers for VHL sequencing. (XLS $35 \mathrm{~kb}$ )

Additional file 3: Table S3. Summary of cell cultures established. (XLS $40 \mathrm{~kb}$ )

Additional file 4: Table S4. Doubling times of VHLmut and VHLWt cCRCC cultures. (XLS $25 \mathrm{~kb}$ )

Additional file 5: Table S5. Differentially expressed genes between VHLmut and VHLWt cell cultures. (XLSX $58 \mathrm{~kb}$ )

Additional file 6: Table S6. Differrentially expressed networks between VHLmut and VHLwt cell cultures. (XLS 66 kb)

Additional file 7: Table S7. Genes associated with the VHLmut networks shown in Fig. 6. (XLSX 14 kb)

Additional file 8: Table S8. Differentially expressed genes between matched tumor tissue and VHLmut cultures. (XLSX 1.05 mb)

Additional file 9: Table S9. Differentially expressed genes between matched tumor tissue and VHLmut cultures. (XLSX 16 kb)

Additional file 10: Figure S1. Copy number profiles of primary cultures and matched primary tumors and adjacent normal tissues. Figure S2. Morphology of VHLmut vs. VHLwt cultures. Figure S3. VHLwt cells do not express distal tubule markers. Figure S4. Xenografts derived from RCC\#243mut and RCC\#407mut cultures. Figure S5. Hierarchical clustering heatmap of Pearson correlation coefficients between matched VHLmut cells, VHLwt cells and primary tumor tissues. Figure S6. Functional annotation of 211 VHLmut-associated genes (red) and 382 VHLWt-associated genes. Figure S7. Enrichment map of tumor tissue vs. VHLmut culture gene expression profiles. (PPTX $10688 \mathrm{~kb}$ )

\section{Abbreviations}

bFGF, basic fibroblast growth factor; CA9, carbonic anhydrase IX; cCRCC, clear cell renal cell carcinoma; CNA, copy number alteration; DNA, deoxyribonucleic acid; DSFM, defined serum-free media; EGF, epidermal growth factor; FBS, fetal bovine serum; GO, gene ontology; GSEA, gene set enrichment analysis; HIF, hypoxia inducible factor; IMDM, Iscove's modified Dulbecco's media; KEGG, Kyoto encyclopedia of genes and genomes; NOD/SCID/IL2RY-/-, Nonobese diabetic/severe combined immunodeficient/interleukin 2-receptor gamma knockout; RCC, renal cell carcinoma; RNA, ribonucleic acid; RNAseq, RNA sequencing; SNP, single nucleotide polymorphism; TCGA, the cancer genome atlas; TGF $\beta$, transforming growth factor beta; TNF, tumor necrosis factor; VHL, von Hippel Lindau; VHLmut, von Hippel Lindau mutant; VHLwt, von Hippel Lindau wild-type

\section{Acknowledgements}

We are grateful to Laura Legere, Rehab Chahin, Ajla Meheljic, Hannah Chung, and the UHN Program in Biospecimen Sciences for tissue acquisition. 


\section{Funding}

Funding for this work was provided to LA by the Ontario Institute for Cancer Research and CG by the Australian National Health and Medical Research Council, the Canadian Institutes for Health Research in partnership with Kidney Cancer Canada, and by the Royal Australasian College of Physicians. This research was funded in part by the Ontario Ministry of Health and Long Term Care. The views expressed do not necessarily reflect those of the OMOHLTC.

\section{Availability of data and materials}

The RNAseq data set supporting the results of this article has been deposited in NCBI's Gene Expression Omnibus [21] and are accessible through GEO Series accession number GSE74958 (http://www.ncbi.nlm.nih.gov/geo/query/ acc.cgi?acc $=$ GSE74958)

\section{Authors' contributions}

$\mathrm{NL}, \mathrm{CG}$ and $\mathrm{LA}$ were responsible for conception and design, data analysis and interpretation, and manuscript writing. $\mathrm{NL}, \mathrm{AA}$ and JP were responsible for collection and assembly of data. KB and NS were responsible for RNAseq and SNP array data analysis, respectively. MR, NF, RJH, GK, AZ, AE, AF and MASG provided patient tissues. JM and MASG were involved in conception and design. All authors provided final approval of the manuscript.

\section{Competing interests}

The authors declare that they have no competing interests.

\section{Consent for publication}

Not applicable. All information relating to patient samples is entirely unidentifiable and there are no details on individuals reported within the manuscript.

\section{Ethics approval and consent to participate}

Patient-derived ccRCC samples were obtained from the University Health Network (UHN) and the Cooperative Health Tissue Network from patients providing written consent under UHN Research Ethics Board approval, protocol \#09-0828-T. All animal studies were performed in accordance with the Canadian Council on Animal Care with the approval of the UHN Anima Care Committee, animal use protocol \#1980.

\section{Author details}

${ }^{1}$ Department of Medical Biophysics, University of Toronto, Toronto, ON Canada. ${ }^{2}$ School of Biomedical Sciences and Pharmacy, University of Newcastle, Hunter Medical Research Institute, Newcastle, NSW, Australia. ${ }^{3}$ Princess Margaret Cancer Centre, University Health Network, Toronto, ON, Canada. ${ }^{4}$ Donnelly Centre and Banting \& Best Department of Medical Research, University of Toronto, Toronto, ON, Canada. ${ }^{5}$ Laboratory Medicine Program, Department of Pathology, University Health Network, Toronto, ON, Canada.

\section{Received: 4 February 2016 Accepted: 8 July 2016 Published online: 16 July 2016}

\section{References}

1. Baldewijns MM, van Vlodrop IJ, Schouten LJ, Soetekouw PM, de Bruine AP, van Engeland M. Genetics and epigenetics of renal cell cancer. Biochim Biophys Acta. 2008;1785(2):133-55.

2. Nickerson ML, Jaeger E, Shi Y, Durocher JA, Mahurkar S, Zaridze D, Matveev V Janout $\mathrm{V}$, Kollarova $\mathrm{H}$, Bencko $\mathrm{V}$, et al. Improved identification of von HippelLindau gene alterations in clear cell renal tumors. Clin Cancer Res. 2008; 14(15):4726-34

3. Linehan WM, Rubin JS, Bottaro DP. VHL loss of function and its impact on oncogenic signaling networks in clear cell renal cell carcinoma. Int J Biochem Cell Biol. 2009;41(4):753-6.

4. Beroukhim R, Brunet JP, Di Napoli A, Mertz KD, Seeley A, Pires MM, Linhart D, Worrell RA, Moch H, Rubin MA, et al. Patterns of gene expression and copy-number alterations in von-hippel lindau disease-associated and sporadic clear cell carcinoma of the kidney. Cancer Res. 2009;69(11):4674-81.

5. van Staveren WC, Solis DY, Hebrant A, Detours V, Dumont JE, Maenhaut C. Human cancer cell lines: experimental models for cancer cells in situ? for cancer stem cells? Biochim Biophys Acta. 2009;1795(2):92-103.
6. Brugarolas J. Molecular genetics of clear-cell renal cell carcinoma. J Clin Oncol. 2014:32(18):1968-76.

7. The Cancer Genome Atlas Research N. Comprehensive molecular characterization of clear cell renal cell carcinoma. Nature. 2013:499(7456):43-9.

8. Lee J, Kotliarova S, Kotliarov Y, Li A, Su Q, Donin NM, Pastorino S, Purow BW, Christopher N, Zhang W, et al. Tumor stem cells derived from glioblastomas cultured in bFGF and EGF more closely mirror the phenotype and genotype of primary tumors than do serum-cultured cell lines. Cancer Cell. 2006;9(5):391-403.

9. Pollard SM, Yoshikawa K, Clarke ID, Danovi D, Stricker S, Russell R, Bayani J, Head R, Lee M, Bernstein M, et al. Glioma stem cell lines expanded in adherent culture have tumor-specific phenotypes and are suitable for chemical and genetic screens. Cell Stem Cell. 2009;4(6):568-80.

10. van de Wetering $M$, Francies HE, Francis JM, Bounova G, lorio F, Pronk $A$ van Houdt W, van Gorp J, Taylor-Weiner A, Kester L, et al. Prospective derivation of a living organoid biobank of colorectal cancer patients. Cell. 2015;161(4):933-45.

11. Trapnell C, Williams BA, Pertea G, Mortazavi A, Kwan G, van Baren MJ, Salzberg SL, Wold BJ, Pachter L. Transcript assembly and quantification by RNA-Seq reveals unannotated transcripts and isoform switching during cell differentiation. Nat Biotechnol. 2010;28(5):511-5.

12. Packer $L$, Fuehr K. Low oxygen concentration extends the lifespan of cultured human diploid cells. Nature. 1977;267(5610):423-5.

13. Parrinello S, Samper E, Krtolica A, Goldstein J, Melov S, Campisi J. Oxygen sensitivity severely limits the replicative lifespan of murine fibroblasts. Nat Cell Biol. 2003;5(8):741-7.

14. Wykoff CC, Beasley NJ, Watson PH, Turner KJ, Pastorek J, Sibtain A, Wilson GD, Turley $\mathrm{H}$, Talks KL, Maxwell PH, et al. Hypoxia-inducible expression of tumorassociated carbonic anhydrases. Cancer Res. 2000;60(24):7075-83.

15. Tostain J, Li G, Gentil-Perret A, Gigante M. Carbonic anhydrase 9 in clear cell renal cell carcinoma: a marker for diagnosis, prognosis and treatment. Eur J Cancer. 2010;46(18):3141-8

16. Tong GX, Yu WM, Beaubier NT, Weeden EM, Hamele-Bena D, Mansukhani MM, OToole KM. Expression of PAX8 in normal and neoplastic renal tissues: an immunohistochemical study. Mod Pathol. 2009:22(9):1218-27.

17. Poleev A, Fickenscher H, Mundlos S, Winterpacht A, Zabel B, Fidler A, Gruss P, Plachov D. PAX8, a human paired box gene: isolation and expression in developing thyroid, kidney and Wilms' tumors. Development. 1992;116(3):611-23.

18. Pfleiderer G, Mossner E, Schenk R. Alkaline phosphatase isoenzymes in human kidney and urine, immunohistochemical, immunological and biochemical characterization. Histochemistry. 1984:80(2):145-8.

19. Baer PC, Bereiter-Hahn J, Schubert R, Geiger H. Differentiation status of human renal proximal and distal tubular epithelial cells in vitro: differential expression of characteristic markers. Cells Tissues Organs. 2006;184(1):16-22.

20. Truong LD, Shen SS. Immunohistochemical diagnosis of renal neoplasms. Arch Pathol Lab Med. 2011;135(1):92-109.

21. Edgar R, Domrachev M, Lash AE. Gene expression omnibus: NCBI gene expression and hybridization array data repository. Nucleic Acids Res. 2002;30(1):207-10

22. Merico D, Isserlin R, Stueker O, Emili A, Bader GD. Enrichment map: a network-based method for gene-set enrichment visualization and interpretation. PLoS One. 2010;5(11):e13984.

23. Subramanian A, Tamayo P, Mootha VK, Mukherjee S, Ebert BL, Gillette MA, Paulovich A, Pomeroy SL, Golub TR, Lander ES, et al. Gene set enrichment analysis: a knowledge-based approach for interpreting genome-wide expression profiles. Proc Natl Acad Sci U S A. 2005:102(43):15545-50.

24. Coulombel L, Eaves C, Kalousek D, Gupta C, Eaves A. Long-term marrow culture of cells from patients with acute myelogenous leukemia. Selection in favor of normal phenotypes in some but not all cases. J Clin Invest. 1985;75(3):961-9.

25. Coulombel L, Kalousek DK, Eaves CJ, Gupta CM, Eaves AC. Long-term marrow culture reveals chromosomally normal hematopoietic progenitor cells in patients with Philadelphia chromosome-positive chronic myelogenous leukemia. N Engl J Med. 1983;308(25):1493-8.

26. Ochs RL, Fensterer J, Ohori NP, Wells A, Gabrin M, George LD, Kornblith P. Evidence for the isolation, growth, and characterization of malignant cells in primary cultures of human tumors. In Vitro Cell Dev Biol Anim. 2003;39(1-2):63-70.

27. Detrisac CJ, Sens MA, Garvin AJ, Spicer SS, Sens DA. Tissue culture of human kidney epithelial cells of proximal tubule origin. Kidney Int. 1984;25(2):383-90.

28. Gedye C, Ailles L. Isolation and characterization of cancer stem cells in vitro. Methods Mol Biol. 2013;946:181-204. 
29. Gedye C, Sirskyj D, Lobo NC, Hyatt E, Evans A, Finelli A, Fleshner NE, Hamilton RJ, Kulkarni GS, Robinette M, et al. Essential experimental steps and estimates of renal carcinoma initiating cells. ASCO Meeting Abstracts. 2014;32(15_suppl):11127.

30. Klatte T, Rao PN, de Martino M, LaRochelle J, Shuch B, Zomorodian N, Said J, Kabbinavar FF, Belldegrun AS, Pantuck AJ. Cytogenetic profile predicts prognosis of patients with clear cell renal cell carcinoma. J Clin Oncol. 2009;27(5):746-53.

31. Gerlinger M, Rowan AJ, Horswell S, Larkin J, Endesfelder D, Gronroos E, Martinez P, Matthews N, Stewart A, Tarpey P, et al. Intratumor heterogeneity and branched evolution revealed by multiregion sequencing. N Engl J Med. 2012;366(10):883-92.

32. Zhou L, Chen J, Li Z, Li X, Hu X, Huang Y, Zhao X, Liang C, Wang Y, Sun L, et al. Integrated profiling of MicroRNAs and mRNAs: MicroRNAs located on Xq27.3 associate with clear cell renal cell carcinoma. PLoS One. 2010; 5(12):e15224

33. Arreola A, Cowey CL, Coloff JL, Rathmell JC, Rathmell WK. HIF1alpha and HIF2alpha exert distinct nutrient preferences in renal cells. PLoS One. 2014;9(5):e98705.

34. Tun HW, Marlow LA, von Roemeling CA, Cooper SJ, Kreinest P, Wu K, Luxon BA, Sinha M, Anastasiadis PZ, Copland JA. Pathway signature and cellular differentiation in clear cell renal cell carcinoma. PLoS One. 2010;5(5):e10696.

35. Nilsson $\mathrm{H}$, Lindgren D, Mandahl Forsberg A, Mulder $\mathrm{H}$, Axelson $\mathrm{H}$, Johansson ME. Primary clear cell renal carcinoma cells display minimal mitochondrial respiratory capacity resulting in pronounced sensitivity to glycolytic inhibition by 3-Bromopyruvate. Cell Death Dis. 2015;6:e1585.

36. Johnson $A B$, Denko $N$, Barton MC. Hypoxia induces a novel signature of chromatin modifications and global repression of transcription. Mutat Res. 2008;640(1-2):174-9.

37. Yoshihara K, Shahmoradgoli M, Martinez E, Vegesna R, Kim H, Torres-Garcia W, Trevino V, Shen H, Laird PW, Levine DA, et al. Inferring tumour purity and stromal and immune cell admixture from expression data. Nat Commun. 2013;4:2612

38. Dudderidge TJ, Stoeber K, Loddo M, Atkinson G, Fanshawe T, Griffiths DF, Williams GH. Mcm2, Geminin, and Kl67 define proliferative state and are prognostic markers in renal cell carcinoma. Clin Cancer Res. 2005;11(7):2510-7.

\section{Submit your next manuscript to BioMed Central and we will help you at every step:}

- We accept pre-submission inquiries

- Our selector tool helps you to find the most relevant journal

- We provide round the clock customer support

- Convenient online submission

- Thorough peer review

- Inclusion in PubMed and all major indexing services

- Maximum visibility for your research

Submit your manuscript at www.biomedcentral.com/submit

) Biomed Central 